\title{
O PRINCÍPIO DA DIGNIDADE DA PESSOA HUMANA
}

\author{
Rosa Maria Guimarães Alves ${ }^{1}$ \\ ${ }^{1}$ Advogada e Mestre em Direito Processual Civil. Ministra as disciplinas Teoria Geral do Processo e Direito Processual Civil na \\ Faculdade de Direito da Universidade do Oeste Paulista - Unoeste.
}

\section{RESUMO}

O presente artigo trata do princípio da dignidade humana. Cumpre esclarecer que ele originou-se de um insight vivido no Campus da Universidade que revelou a pertinência da utilização da concepção ontológica no estudo do princípio da dignidade humana. Por isso, o texto, em seu início, está permeado de aspectos filosóficos, buscando demonstrar que o princípio em pauta se adequa à concepção metafísica e axiológica. Posteriormente, há referência aos direitos humanos e intenta-se o aprofundamento do conceito de dignidade humana sob o aspecto ontológico, para, finalmente, visualizá-lo como princípio a ser aplicado no campo jurídico.

Palavras-chave: Direitos Humanos, Dignidade da Pessoa Humana, Concepção Ontológica.

\section{THE PRINCIPLE OF HUMAN DIGNITY}

\begin{abstract}
This article deals with the principle of human dignity. It should be clarified that it stemmed from an insight lived on the campus of the University, revealed that the appropriateness of the conception study of the ontological principle of human dignity. Therefore the text, at its beginning, is permeated with philosophical aspects, trying to demonstrate that the principle in question is suitable for the conception and axiological metaphysics. Then, there is reference to human rights and it seeks to deepen the concept of human dignity on the ontological aspect, to finally see it as a principle to be applied in the legal field.

Keywords: Human Rights, Human Dignity, Ontological Conception.
\end{abstract}




\section{INTRODUÇÃO}

Espaço amplo. Áreas verdes bem cuidadas. Flores multicoloridas. Árvores que abrigam do sol escaldante e, outras, majestosas. Bancos convidando ao descanso, à conversação e, mesmo, à reflexão. O sussurrar da fonte e as águas subindo e descendo, numa dança inventada pelo homem, porém, sucumbindo ao vento morno da natureza e espargindo pequenas gotas ao redor de si mesma. Alunos aproveitando o rápido intervalo entre aulas para tomar um lanche e, outros, conversando.

Faço parte deste cenário, discutindo com uma aluna as questões do seu projeto de iniciação científica, cujo foco principal é a dignidade da pessoa humana. $O$ tema abre um leque de questões que nos incitam a ingressar no campo da sociologia, da antropologia, da psicologia e outros logos mais. Um aluno aproxima-se e diz que precisa conversar comigo. Intenta afastar-se, mas convido-o a ficar, dizendoIhe do que eu e minha orientanda estamos tratando. Continuamos a conversa e ele se engaja na discussão e, de repente, percebo que a pesquisadora e ele estão debatendo sobre determinada questão pertinente ao tema da pesquisa. $\mathrm{O}$ entusiasmo de ambos é contagiante e, por um momento (único) sinto a magia da Universidade - Universo de idéias, de pensamentos, de opiniões - tudo a convergir para o aprendizado.

Lembro, então, de lições de filosofia apontando que, diante do espetáculo da natureza, o homem experimenta sentimentos variados: medo, resignação, coragem, incompreensão, admiração, perplexidade e que são estes sentimentos os responsáveis por questionamentos. É que a realidade (onde também está compreendida a natureza) leva às indagações e ao pensar: foi desta maneira que surgiu a filosofia, traduzida do grego como amor ao conhecimento.
Recordo Sócrates (marco divisório desta busca de conhecimento, porquanto se fala em filósofos Pré - Socráticos e Pós - Socráticos) e o "seu querer aprender": método de investigação que encaminha o pensamento em direção à essência das coisas; sua célebre frase "Só sei que nada sei", significando a infinitude do saber e, neste contexto, indago: como definir a dignidade da pessoa humana? É possível precisá-la, conferir-lhe contornos definidos, concretizá-la? Penso que não. Tal tarefa é temerária. Melhor visualizá-la na teoria das idéias, na metafísica.

Busco, então, verificar o tema e deparo com o ensinamento de Coelho (2009, p. 172) colhido de preleção percuciente do eminente jurista Reale. O constitucionalista mencionado assevera que:

Em um dos seus mais refinados escritos - Pessoa, Sociedade e História - Miguel Reale afirmou que toda pessoa é única e que nela já habita o todo universal, o que faz dela um todo inserido no todo da existência humana; que, por isso, ela deve ser vista antes como centelha que condiciona a chama e a mantém viva, e na chama a todo instante crepita, renovando-se criadoramente, sem reduzir uma à outra; e que, afinal, embora precária a imagem, o que importa é tornar claro que dizer pessoa é dizer singularidade, intencionalidade, liberdade, inovação e transcendência, o que é impossível em qualquer concepção transpersonalista, a cuja luz a pessoa perde os seus atributos como valor-fonte da experiência ética para ser vista como simples "momento de um ser transpessoal" ou peça de um gigantesco mecanismo, que, sob várias denominações, pode ocultar sempre o mesmo "monstro frio": "coletividade", "espécie", "nação", "classe", "raça", "idéia", "espírito universal", ou "consciência coletiva". 
Conclui, então, que é "sob essa concepção metafísica do ser humano que reputamos adequado analisar a dignidade da pessoa humana".

A assertiva acima reforça a convicção de compreender a dignidade da pessoa humana, no campo dos valores filosóficos.

Com efeito, também Sarlet (2007, p. 39), comunga o mesmo pensamento de Miguel Reale e salienta que:

[...] a fundamentação metafísica da dignidade da pessoa humana, que,na sua manifestação jurídica, significa uma última garantia da pessoa humana em relação a uma total disponibilidade por parte do poder estatal e social".

Experimento, então, outra experiência que corrobora a convicção supra.

É que, no tocante ao poder social, pude constatar, dias depois, na participação do Encontro de Ensino, Pesquisa e Extensão promovido pela Universidade, em meio a diversidade de alunos de outros cursos e, também, de outras Universidades, quando ingressei no auditório onde se discutia a Ética na Pesquisa, ouvi atentamente um Professor de Medicina da Faculdade de Botucatu. Para minha surpresa, ele terminou sua exposição salientando que a pesquisa, na área médica, deve respeitar a dignidade do ser humano.

Recordo o ilustre palestrante dizendo sobre as experiências médicas realizadas no período da Segunda Guerra Mundial. Os nazistas, usando como cobaias, as pessoas enclausuradas nos campos de concentração. Um dos horrores da guerra que buscava uma raça pura: a ariana. Nesse ponto lembro o dito espanhol "El sueño de la razon produce monstrios".

Reflito, então, que, com o final da insana guerra, surge uma tomada de consciência universal com a Declaração Universal dos Direitos Humanos da Organização das Nações
Unidas, realizada no ano de 1948. Pois bem. Do caos, exsurge o valor do fundamento da vida social, trazendo a lume uma lei, de grandeza ímpar, reconhecendo a prioridade da natureza ética cuja validade é universal.

Nesse passo, compreendo a afirmação de Rizzato Nunes (2002, p. 50), quando menciona ter sido a experiência nazista a fonte da consciência universal acerca da dignidade da pessoa humana, transformando-a em valor éticojurídico.

Tudo fica, então, de clareza solar. O princípio da dignidade da pessoa humana deve ser estudado e entendido em sua concepção ontológica. Necessário conhecê-lo sob este aspecto e saber sobre sua origem.

\section{Origem remota da dignidade da pessoa humana}

Anteriormente à Declaração dos Direitos Humanos da Organização das Nações Unidas a história dá conta que somente em dois documentos anteriores havia menção aos direitos humanos: o primeiro refere-se à formação do Estado norte-americano - a Declaração de Independência dos Estados Unidos, de 1776 e, o outro, à mudança de poder da França - a Declaração de Direitos do Homem e do Cidadão, de 1789.

Entretanto, o foco dos documentos citados eram os direitos humanos e não, especificamente, a dignidade da pessoa humana. Esta era tratada apenas na filosofia e na religião, porquanto as normas de Direito Humanitário do século XIX objetivavam o tratamento das vítimas de guerra e a proteção humanitária dirigia-se aos militares fora de combate (feridos, doentes, náufragos e prisioneiros) e às populações civis, declarando limites ao uso da violência em guerras. (lições extraídas do artigo A Declaração Universal dos Direitos Humanos - 50 anos, Outubro de 1998 - p. 243/267). 
De outra parte, focalizando-se apenas os direitos humanos, vê-se claramente que sua conotação é histórica, não se confundindo com os direitos naturais e absolutos. Com muita propriedade, Silva (1998, p. 169) afirma que eles.

São históricos, como qualquer direito. Nascem, modificam-se e desaparecem. Eles apareceram com a revolução burguesa e evoluem, ampliamse com o correr dos tempos. Sua historicidade rechaça toda fundamentação baseada no direito natural, na essência do homem ou na natureza das coisas.

Esta historicidade dos direitos humanos é bem explicada por Bobbio (1992, p. 5) ao assinalar que determinados acontecimentos, no decorrer da historia, conduziram ao aparecimento destes direitos. Assim, as guerras de religião levaram ao surgimento da liberdade religiosa; a luta contra os soberanos absolutos proporcionou o nascimento das liberdades civis e, deste modo, sucessivamente, numa relação de causa e efeito própria da evolução do homem.

Em sentido idêntico, Arendt (1979, p. 34) esclarece que os direitos humanos não são um dado, mas um construído, uma invenção humana, em constante processo de construção e reconstrução.

O mesmo não ocorre com a dignidade da pessoa humana: ela é inerente ao ser humano.

Destarte, em que pese o fato dela não despontar nos direitos humanos do século XVIII (liberdade, igualdade e fraternidade), era o ponto fulcral deles, estava latente em suas entranhas. No cerne dos direitos humanos encontra-se a dignidade da pessoa.

Ademais, Sarlet (2007, p. 71) entende que, a despeito dos direitos humanos encontrarem o seu fundamento no princípio da dignidade da pessoa humana, ela pode ir além deles, ou seja, gestar direitos fundamentais autônomos.

\section{Do Princípio da Dignidade da Pessoa Humana}

A dignidade é um valor intangível e direito essencial da pessoa humana. No dizer de São Tomas de Aquino (2004, p. 51) é impossível se encontrar uma definição para o conceito de dignidade da pessoa humana, ressaltando que "o termo dignidade é algo absoluto e pertence à essência". Complementando esta assertiva, Montoro (2000, p. 23) assegura a necessidade de se ter por norte que a pessoa humana é o valor fundamental da ordem jurídica, sendo, portanto, a fonte das fontes do direito.

Deste modo, se os direitos humanos são históricos e temporais, a dignidade humana, extraída das entranhas deste direito, é valor supremo e atemporal.

Neste contexto, Sznaniawski (2005, p. 141) elucida a questão, ao asseverar que:

A idéia de que todo ser humano
é possuidor de dignidade é
anterior ao direito, não
necessitando, por conseguinte,
ser reconhecida juridicamente
para existir. Sua existência e
eficácia prescindem de
legitimação, mediante
reconhecimento expresso pelo
ordenamento jurídico. No
entanto, dada a importância da
dignidade, comor princípio
basilar que fundamenta o
Estado Democrático de Direito,
esta vem sendo reconhecida,
de longa data, pelo
ordenamento jurídicor dos
povos civilizados e
democráticos, como princípio
fundamental, comor valor
unificador dos demais direitos
fundamentais, inserido nas
Constituições, como princípio
jurídico fundamental". r

Compreende-se, destarte, porque a Declaração Universal dos Direitos Humanos da Organização das Nações Unidas traz em seu Preâmbulo "o reconhecimento da dignidade inerente a todos os membros da família humana e 
de seus direitos iguais e inalienáveis" assentado no "fundamento da liberdade, da justiça e da paz no mundo" (grifo não constante no original).

Firmada, pois, a universalidade e a indivisibilidade desses direitos porque, basta ser pessoa humana para ter o direito à dignidade preconizada, imbuída de contornos sociais, econômicos e culturais.

De outra parte, Rizzato Nunes (2002, p. 46) afirma que dignidade, apesar de pertencer à essência do ser, é um conceito que foi sendo formado no transcorrer da história, chegando ao século XXI como um valor supremo. Todavia, nenhuma pessoa vive isolada e, a vida em sociedade, confere a ela um acréscimo de dignidade. Por isso, não pode o homem agir contra a própria dignidade.

Importa salientar, também, o pensamento de Sarlet (2008, p. 63) no tocante ao conceito de dignidade da pessoa humana frente à sociedade. Confira-se:

[...] a qualidade intrínseca e distintiva reconhecida em cada ser humano que o faz merecedor do mesmo respeito e consideração por parte do Estado e da comunidade, implicando, neste sentido, um complexo de direitos e deveres fundamentais que assegurem à pessoa tanto contra todo $\mathrm{e}$ qualquer ato de cunho degradante e desumano, como venham a the garantir as condições existenciais mínimas para uma vida saudável, além de propiciar e promover sua participação ativa e coresponsável nos destinos da própria existência e da vida em comunhão com os demais seres humanos.

Por outro lado, há doutrinadores de escol que tecem críticas à concepção metafísica da dignidade humana. Os pontos mais importantes da posição por eles adotada são os seguintes: 1a dignidade da pessoa humana é apenas uma criação humana (em contraposição ao conceito que ela é inerente ao homem); 2- a concepção ontológica dificulta sua aplicação no campo jurídico, podendo servir a interesses particulares e arbitrários.

Contudo, no que toca à primeira crítica, difícil aceitá-la.

Com efeito, impossível conceber que a dignidade é criação humana. Pode-se pensar que o seu conceito é que foi sendo formado no transcorrer da história, porque o "valor" dignidade é inerente ao homem. Fala-se em criação humana face à dificuldade de conceituar algo que é de essência do ser humano: a dignidade preexiste ao Direito.

Quanto ao segundo ponto da crítica, importa lembrar Reale (1978, p. 81-82) afirmando que 0 aspecto ontológico (ou axiológico) proporciona o ajuste de modelos jurídicos às necessidades de um mundo cada vez mais complexo. Destarte, a concepção ontológica de dignidade da pessoa humana aproxima-a da realidade contemporânea.

Além do mais, sabido que, no campo do Direito, existem palavras cujo conteúdo não é possível precisar. Basta lembrar "Bem-Comum" (utilizado desde de 1916, no artigo 5º da Lei de Introdução ao Código Civil) cuja definição mais aceita não é de nenhum jurista e sim do Papa João XXIII. Ou, então, Justiça: o conceito mais apropriado remonta ao filósofo Aristóteles.

Aliás, esta dificuldade pode ser compreendida na lição precisa do professor Ferraz Junior (1994, p. 41) quando aduz que o termo Justiça representa um valor e o seu significado somente pode ser visto sob o aspecto zetético. Esclarece:

Zetética vem de zetein que significa perquirir, dogmática vem de dokein que significa ensinar, doutrinar. Embora entre ambas não haja uma linha divisória radical (toda investigação acentua mais um enfoque que o outro, mas sempre tem os dois), a sua 
diferença é importante. O enfoque dogmático releva o ato de opinar e ressalta algumas opiniões, pondo-as em dúvida. Questões zetéticas têm uma função especulativa explícita e são infinitas. Questões dogmáticas têm uma função diretiva explícita e são finitas. Nas primeiras, o problema tematizado é configurado como um ser (que é algo?). Nas segundas, a situação nelas captadas se configura como um dever-ser (como deve-ser algo?). Por isso, o enfoque zetético visa a saber o que é uma coisa. Já o enfoque dogmático se preocupa em possibilitar uma decisão e orientar a ação.

O mesmo ocorre com dignidade da pessoa humana. Sua valoração pode ensejar questionamentos infinitos porque ela configura (conforme já visto) um "ser", no sentido de essência. De outra parte, preocupar-se com a falta de precisão do conceito de dignidade não procede.

Com efeito, nem mesmo os cientistas conseguem que suas invenções sejam utilizadas para o intento concebido. O notável Einstein (1994, p. 161), preocupado com o mau uso das descobertas científicas, adverte que:

Nós, cientistas, cujo trágico destino tem sido ajudar a fabricar os mais hediondos e eficazes métodos de aniquilação, devemos considerar nossa missão fazer tudo o que estiver em nosso poder para evitar que essas armas sejam usadas para propósitos brutais. Que missão poderia ser mais importante para nós? Que finalidade social estaria mais próxima de nossos corações?

Ainda, angustiado com a fabricação da bomba atômica (p. 162), obtida por meio de suas experiências e teorias desabafa:

Por uma penosa experiência, aprendemos que o pensamento racional não é suficiente para resolver os problemas de nossa vida social. O intelecto tem um olho aguçado para os métodos e ferramentas, mas é cego quanto aos fins e valores. A ciência pode apenas determinar o que é, e não o que deve ser. Esse é o campo da ética e da religião.

Por fim, preocupado com os valores morais da juventude e expondo a retidão de seu caráter, adverte (p. 277):

\begin{abstract}
A função da educação não pode limitar à transmissão de conhecimentos. Ela deve ajudar o jovem a crescer num espírito tal que os princípios éticos fundamentais (de honradez, veracidade, respeito ao próximo, solidariedade) sejam para ele como o ar que ele respira. O mero ensino não pode fazer isso.
\end{abstract}

\section{A Dignidade da Pessoa Humana no Plano do Direito}

No plano do direito, para melhor entendimento deste princípio, o primeiro passo é traçar considerações de ordem geral.

Consoante já destacado, a pessoa humana é considerada enquanto valor e o princípio correspondente, aqui retratado, é absoluto, devendo prevalecer, indiscutivelmente e infinitamente, sobre qualquer outro valor ou princípio.

O que caracteriza o ser humano e o faz dotado de dignidade especial, é que ele nunca pode ser meio para os outros, mas fim em si mesmo.

Moraes, (1997, p. 46) ao interpretar o art. 28 da Declaração dos Direitos Humanos das Nações Unidas, estabelece:

os direitos humanos
fundamentais não podem ser
utilizados como um verdadeiro
escudo protetivo da prática de
atividades ilícitas, nem
tampouco como argumento


para afastamento ou diminuição da responsabilidade civil ou penal por atos criminosos, sob pena de total consagração ao desrespeito a um verdadeiro Estado de Direito. Os direitos e garantias fundamentais consagrados pela Constituição Federal, portanto, não são ilimitados, uma vez que encontram seus limites aos demais direitos igualmente consagrados pela Magna Carta (principio da relatividade ou convivência das liberdades públicas). Dessa forma, quando houver conflito entre dois ou mais direitos e garantias fundamentais, o intérprete deve utilizar-se do princípio da concordância ou da harmonização, de forma a coordenar e combinar os bens jurídicos em conflito, evitando o sacrifício total de uns em relação aos outros, realizando uma redução do âmbito de alcance de cada qual (contradição dos princípios), sempre em busca do verdadeiro significado da norma e da harmonia do texto constitucional com suas finalidades precípuas.

Por isso, premissa básica é o reconhecimento no homem de sua própria dignidade, tornando-se desprezáveis eticamente condutas incompatíveis com tal condição, porque o princípio da dignidade da pessoa humana obriga ao inafastável compromisso com 0 absoluto e irrestrito respeito à identidade e à integridade de todo ser humano.

No contexto internacional a Conferência de Viena de 1993 deu sequência à Declaração Universal de 1948 - o lema era a universalidade, indivisibilidade e interdependência de todos os Direitos Humanos. Com isso, confere aos Direitos Humanos um valor (caráter axiológico).

De outra parte, das lições de Coelho (2009, p. 174), desponta que, mesmo não se atribuindo ao principio da dignidade da pessoa humana 0 valor de princípio absoluto - metajurídico, pré-constituinte ou préconstitucional, é um princípio que está acima dos demais. Destarte, só pode ser confrontado com ele mesmo, ou seja, quando duas ou mais pessoas em conflito, fundamentam suas pretensões no princípio da dignidade humana.

Ressalta, também, a diversidade de opiniões acerca do princípio em comento, bem como o interesse que ele desperta no campo jurídico ao mencionar que (2009, p. 176):

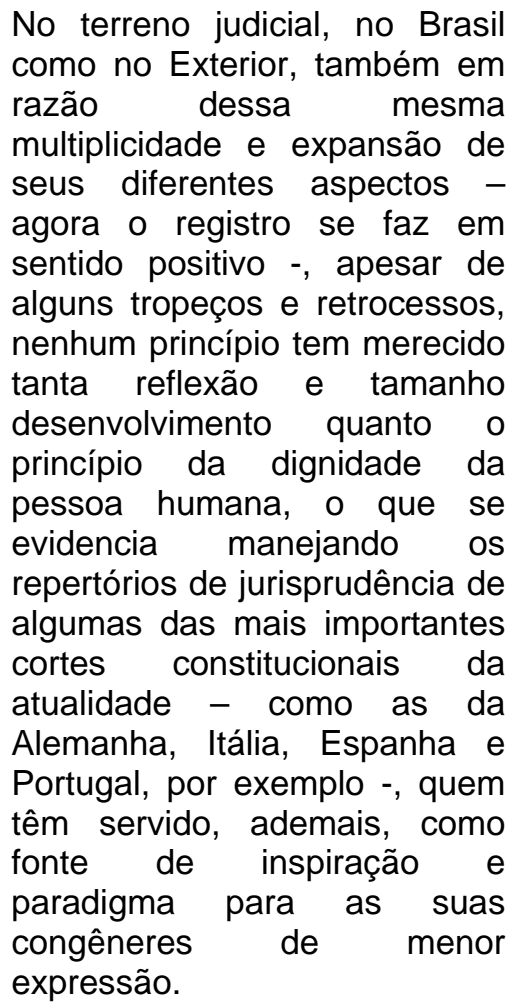

Por outro lado, é sabido que nenhuma lei pode contrariar o disposto na Constituição Federal, sob pena de ser banida do ordenamento jurídico. Neste sentido e considerando-se que a dignidade humana está regrada na Carta Magna de 1988, conseqüência é que o princípio aqui tratado irradia seus efeitos sobre todo e qualquer ramo do direito brasileiro.

Ademais, tratando-se de dignidade da pessoa humana a irradiação do principio ampliase porquanto se refere ao próprio "ser". Somamse a isto, os valores morais que ele contém em seu bojo. 
Neste particular, Tavares da Silva (2001, p. 333-334), de formação civilista, traz questão que bem demonstra a assertiva supra:

Embora as relações familiares tenham conteúdo principalmente afetivo, sua preservação e a preservação de seus membros pelo Direito é indispensável e decorre do princípio da tutela da dignidade da pessoa humana, devendo ter como base a isonomia entre os cônjuges, a igualdade entre os conviventes, a paridade entre os filhos e a proteção de todas as uniões familiares, oriundas ou não de casamento, que hoje têm a garantia constitucional. $\mathrm{Na}$ família, a dignidade da pessoa humana, em todo o alcance dessa expressão, deve ser assegurada tanto no curso das relações familiares como diante de seu rompimento, cabendo ao Direito oferecer instrumentos para impedir a violação desse valor maior".

Da lição supra verifica-se o princípio ora em comento direcionando outro princípio de ordem constitucional, no caso, o da igualdade (ou isonomia). Interessante notar que, subtraindose a dignidade da pessoa humana, não se pode falar em isonomia. Daí a pertinência da afirmação de não se poder cotejá-lo com outro princípio, mesmo constitucional.

No Brasil, a Constituição Federal de 1.988 formaliza a dignidade da pessoa humana em seu artigo $1^{\circ}$, inciso III, ao regrar:

A República Federativa do Brasil, formada pela união indissolúvel dos Estados e Municípios e do Distrito Federal, constitui-se em Estado Democrático de Direito e tem como fundamentos:

$-\ldots$
I - ...
II - a dignidade da pessoa
humana;

Tal norma, conforme já mencionado, deve ser entendida como princípio face a sua magnitude e fluidez.

Arrematando a questão no plano jurídico, bem como comprovando o aspecto atemporal da dignidade humana, sua concepção metafísica e axiológica, segue o entendimento de Moraes (1997, p. 43):

O principio fundamental consagrado pela Constituição Federal da dignidade da pessoa humana apresenta-se em uma dupla concepção. Primeiramente, prevê um direito individual protetivo, seja em relação ao próprio estado, seja em relação aos demais indivíduos. Em segundo lugar, estabelece verdadeiro dever fundamental de tratamento igualitário dos próprios semelhantes. Esse dever configura-se pela exigência do individuo respeitar a dignidade de seu semelhante tal qual a Constituição Federal exige que Ihe respeitem a própria. A concepção dessa noção de dever fundamental resume-se a três princípios do direito romano: honestere (vive honestamente), alterum nonlaedere (não prejudique ninguém) e suum cuique tribuere (dê a cada um o que Ihe é devido)".

Termino esta breve digressão (o princípio que foi tratado é de amplitude ímpar) e, volto a lembrar do cenário objeto do intróito: perfeitamente adequado aos reclamos da dignidade da pessoa humana.

\section{CONSIDERAÇÕES CONCLUSIVAS}

Preliminarmente às considerações conclusivas, necessário reconhecer que a Introdução deste trabalho não se reveste das características próprias de artigo científico. No entanto, não poderia ser de outra forma porque o local e os fatos ali relatados foram decisivos para 
a percepção da transcendência, dos valores filosóficos do princípio da dignidade da pessoa humana.

A experiência vivenciada (atente-se para a utilização dos verbos na primeira pessoa do singular) despertou o interesse de estudar melhor o tema e intentar discorrer sobre ele. Assim, apresenta-se o artigo.

O tema, por sua vez, é instigante e a concepção ontológica adotada aponta para os valores morais que ele comporta.

Além do mais, verifica-se a conotação histórica dos Direitos Humanos. Este fato ressalta claro na divisão de direitos humanos de primeira geração até, atualmente, os de quarta geração. Com efeito, eles são temporais e, por isso, aparecem num crescendo, conforme as necessidades da sociedade à qual servem.

Por outro lado, a dignidade da pessoa humana que está no cerne deles, é atemporal. Explica-se: a dignidade humana sempre existiu, mas, em tempos passados, ela era privilégio dos reis, dos imperadores, dos nobres, dos abastados e de outras pessoas proeminentes no curso da história mundial.

Mas, à medida que os Direitos Humanos vão ganhando vulto, ela, que é o ponto principal, o âmago destes direitos, destaca-se cada vez mais, não para privilegiar somente alguns e sim para atingir cada pessoa, porquanto valor inerente ao homem.

Vale, pois, lembrar Comparato (2000, p. 33) citando que o desenvolvimento dos direitos humanos mostra que os homens são essencialmente iguais, tendo em comum a dignidade, pois são os únicos seres no mundo capazes de amar, descobrir a verdade e criar a beleza.

\section{REFERÊNCIAS}

AQUINO, T. de. Os Pensadores. São Paulo: Nova Cultural Ltda, 2004.
ARENDT, $\mathrm{H}$. As Origens do Totalitarismo. tradução de Roberto Raposo. Rio de Janeiro: Documentário, 1979.

BOBBIO, A era dos direitos. Rio de Janeiro: Campos, 1992.

COELHO, I. M.; MENDES, G. F.a; GONET BRANCO, P. Curso de Direito Constitucional. São Paulo: Editora Saraiva, 2009.

COMPARATO, F. K. Direitos Humanos no Brasil: O passado e o futuro. In: DIREITOS Humanos - Legislação e Jurisprudência Procuradoria Geral do Estado - Grupo de Trabalho de Direitos Humanos. São Paulo: Centro de Estudos, 2000.

EINSTEIN, A. Escritos da maturidade. Rio de Janeiro: Nova Fronteira, 1994.

FERRAZ JUNIOR, T. S. Introdução ao estudo do direito. São Paulo: Atlas, 1994.

GILDOASSU GRACIANO, P. Cultura dos Direitos Humanos. In: DIREITOS Humanos: legislação. São Paulo: Centro de Estudos Procuradoria Geral do Estado, 1999. (Série Estudos, n.12).

MASSA ARZEBE, P. H. Cultura dos Direitos Humanos. In: DIREITOS Humanos: legislação e jurisprudência. São Paulo: Centro de Estudos Procuradoria Geral do Estado, 1999. (Série Estudos n.12).

MONTORO, A. F. Cultura dos Direitos

Humanos. In: DIREITOS Humanos -legislação e jurisprudência. São Paulo: Procuradoria Geral do Estado - Centro de Estudos, 2000.

MORAES, A. de. Direitos humanos fundamentais da democracia. São Paulo: Atlas, 1997.

MORAES, A. de. Direitos Humanos

fundamentais: teoria geral comentários aos artigos $1^{\circ}$. a $5^{\circ}$. Da Constituição da República Federativa do Brasil, doutrina e jurisprudência. São Paulo: Atlas, 2000.

PIOVESAN, F. Direitos Humanos e a Jurisdição Constitucional Internacional. In: DIREITOS Humanos no Cotidiano Jurídico. São Paulo: Centro de Estudos da Procuradoria Geral do Estado, 2004. (Série Estudos n.14).

REALE, M. Pluralismo e Liberdade. São Paulo, Saraiva, 1978.

RIZZATTO NUNES, L. A. O princípio constitucional da dignidade da pessoa humana. São Paulo: Saraiva, 2002. 
SARLET, I. W. Dignidade da pessoa humana e direitos fundamentais na Constituição Federal de 1988. Porto Alegre: Livraria do Advogado, 2007.

SILVA, J. A. da. Proteção constitucional dos direitos humanos no Brasil - evolução histórica e direito atual. Revista da Procuradoria Geral do Estado de São Paulo. Centro de Estudos, 1998.

SZNANIASKI, E. Direitos da Personalidade e sua tutela. São Paulo: Revista dos Tribunais, 2005.

TAVARES DA SILVA, B. R. O projeto do Código Civil e o Direito de Família. Revista da Procuradoria Geral do Estado de São Paulo, Centro de Estudos, 2001. 